\title{
Paleoceanography and Paleoclimatology of the Southern Ocean: A Synthesis of Three Decades of Scientific Ocean Drilling
}

\section{by Gabriel Filippelli}

One of the greatest successes of the Ocean Drilling Program has been the concerted drilling efforts and exciting results recovered from the Southern Ocean, the very cold and very biologically productive ocean basin surrounding Antarctica. Scientific drilling in the ocean and on the Antarctic margin has recovered material from hundreds of sites for scientific analysis. Results from these sites have revealed the dynamic nature of ice-sheet development and ice-margin interactions through time. They also have shown that the Southern Ocean is a critical component in the development and persistence of Antarctic glaciation, a sensitive mixing pool of global water masses, a locus of high biological sedimentation, and that it contains high-resolution records of climate forcing and response; as such, it is one of the most important oceanographic regions in the world. Results from scientific drilling have significantly increased our understanding of Cenozoic to decadal processes that impact the oceanography and climatology of the Southern Ocean and Antarctica. It is now an important time to mine the rich results from scientific drilling over the past several decades, and thus also to provide a scientific framework for future expeditions in this region.

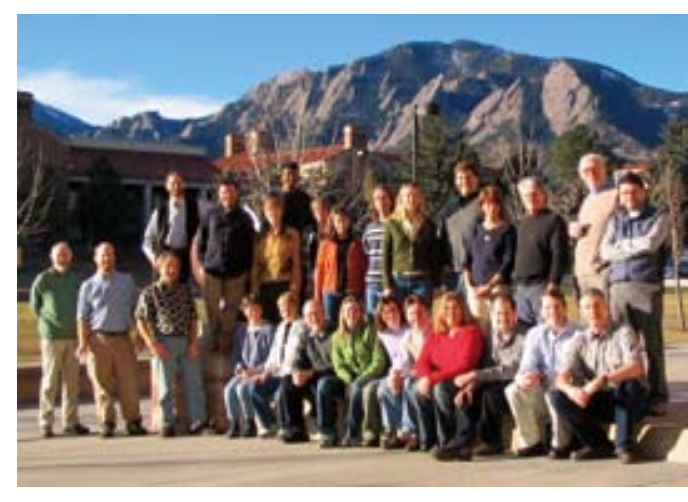

the unknowns sometimes more clearly than the knowns). The final outcome of this workshop will be a set of synthesis papers to be published as a special issue in a journal focused on the following broad themes:

- Steps in climate evolution in the Southern Ocean during the Neogene

- Bio-, magneto-, and radio-chronology in the Southern Ocean

- Development of Antarctic glaciation, Southern Ocean circulation, and productivity during the Cenozoic

- Comparative integration of Antarctic proximal events with Southern Ocean proxies

- Antarctic margin history.

This collection of papers will serve as a science guide to young and old researchers and will provide a framework for planning future research and scientific drilling expeditions to this beautiful, cold, and very critical part of our Earth.

After the dust settled, what seemed like a good idea before the workshop (i.e., conducting a synthesis workshop on a regional or topical theme) has solidified in

To this end, twenty-six researchers from five countries were invited to attend a synthesis workshop on the campus of the University of Colorado in Boulder, in January 2005. This synthesis workshop was funded by the U.S. Science Support Program of the Joint Oceanographic Institutions Inc., with a focus on Southern Ocean paleoceanography and paleoclimatology. We began with plenary overview talks about the critical aspects of Southern Ocean development and continued with poster presentations and vibrant discussions in breakout groups and the group as a whole. The underlying themes of the discussions focused on extracting the knowns, somewhat knowns, and unknowns of various processes, ranging from ice-sheet development, tectonics, ecosystem dynamics, biogeochemical responses, and Southern Ocean thermal structure, on various timescales.

One fantastic product of this workshop was the synergy of top researchers enjoying top science in a retreat-type atmosphere, with quite a few moments of wonder "Why do we not know that yet?" (not an unexpected occurrence whenever you get a group of scientists in a room-we all see my mind at least as imperative for a number of fields related to scientific drilling. Although the push to recover more materials from critical places is what rightfully drives much of the science, mining the physical and intellectual archive resulting from decades of scientific drilling is also an important activity that should be encouraged and funded as a priority mission of the program.

The workshop agenda book, including a list of participants and abstracts, can be accessed at http://www.geology. iupui.edu/research/BIOGEOCHEMLAB/index.htm

\section{Author}

Gabriel Filippelli, Department of Geology, Indiana Univ.Purdue Univ. Indianapolis (IUPUI), Indianapolis, IN 46202-5132, e-mail: filippe@iupui.edu

\section{Related Weblink}

h t t p ://ww w.geology.iupui.edu/research / BIOGEOCHEMLAB/ 